\title{
Assessing Governance Status: Learning from Community Forest User Groups, Nepal
}

\author{
Sameen Raut ${ }^{1,4}$, Suraj Upadhaya ${ }^{2,4}$, Sagar Godar Chhetri ${ }^{1,4 *}$, Murari Raj Joshi ${ }^{3}$
}

\author{
${ }^{1}$ University of Georgia, Warnell School of Forestry and Natural Resources, Athens, USA \\ ${ }^{2}$ Iowa State University, Department of Natural Resource Ecology and Management, Ames, USA \\ ${ }^{3}$ Tribhuvan University, Kathmandu Forestry College, Kathmandu, Nepal \\ ${ }^{4}$ Himalayan Conservation and Research Institute, Dolpa, Nepal \\ *Corresponding author: sagargc44@gmail.com
}

\section{Abstract}

Community forestry practices have proven to be successful in forest resource conservation and utilization in Nepal. Nevertheless, inclusive decision-making processes and equitable benefit-sharing among each household pose significant challenges to the Community Forestry Users Groups (CFUGs). The four key elements of good governance: Participation, Transparency, Accountability, and Predictability, each with their four own local indicators, were employed to measure the governance status in two CFUGs: Bosan and Hattiban Mahila in Kathmandu district. We collected data through a questionnaire survey $(n=95)$, focus group discussions, and key informant surveys. The results showed that the general status of governance in Bosan CFUG was 'Good' (43 out of a total attainable score of 64), whereas that of Hattiban Mahila CFUG was 'Medium'(32 out of a total attainable score of 64). Scores for Transparency, Accountability, and Predictability in Bosan CFUG managed by men and women alike were found to be higher than those of Hattiban Mahila CFUG, which was managed mostly by women. Both the CFUGs received the same score for good governance element: Participation. This study helps policymakers to formulate effective programs for CFUGs members to improve the governance system in such forestry user groups.

Keywords: Community forestry users' group, participation, transparency, accountability, predictability

\section{Introduction}

The forestry sector's contribution to poverty alleviation and the empowerment of marginalized groups can only be achieved by practicing good governance. Governance is the decision-making process, which makes sure whether decisions are administered or not (Lamichhane and Parajuli, 2014; UNESCAP, 2009). Governance can be considered to be good if its attributes align with the principles of governance, otherwise, it is a neutral term (UNESCAP, 2007). Good governance in forestry is a process of systematically managing and utilizing forest resources with participation from all stakeholders, including women, poor, and the disadvantaged groups, in a transparent way so that resources can be harnessed on an equitable basis (UNESCAP, 2007). The idea of good governance focuses on the concept of sustainability in community forestry (Zoysa and Inoue, 2008). Following the definition of sustainable forest management (SFM) by the Food and Agriculture Organization (FAO, 2020), SFM is expected to maintain and enhance the economic, social, and ecological value of all types of forests for the benefit of the present 
generation without compromising the ability to meet the demands of the future generations. Therefore, good governance is considered to be an essential ingredient for achieving the goal of SFM. Numerous development agencies in Nepal are working in community forestry (CF) development and management as a successful initiative for good governance practice promotion focusing on it's different characteristics (Thapa, 2005).

The UNDP (1997) specified a total of nine characteristics of good governance, namely, Participation, the Rule of law, Transparency, Responsiveness, Consensus oriented, Equity, Effectiveness and Efficiency, Accountability, and Strategic vision. However, the ADB (1995) put forth four basic elements of good governance, which include Participation, Transparency, Accountability, and Predictability. This study focused on and utilized these four basic elements to assess the status of governance in two Community Forestry Users Groups (CFUGs) of Kathmandu, Nepal.

People's participation in development mainly focuses on the general planning process, which includes recognizing the development needs, selection and execution of appropriate measures, proper monitoring and evaluation, and benefit-sharing (Hyden and Court, 2002). Opportunities for both men and women to have their voices heard in decisionmaking processes must be created with the help of authorized intermediate institutions that advocate for the interests of the common people (UNDP, 1997). Participation in any governance system must aim to increase ownership to produce better results by being flexible enough for the beneficiaries to get involved in improving the design and implementation of various projects and programs for their benefit (ADB, 1995). Transparency is a perspective of disclosing all the affairs of an institution, especially those related to finances, investments, revenues, and profits, to all the stakeholders, using means that are regular, accessible, and comprehensible (CARE Nepal, 2002; Maharjan et al., 2004). Accountability is the gap between what must be done and what has been done so far (ICIMOD, 2004). The actions of the government must be answered by the authorized public officials, and their performance must be evaluated to ensure that the standards are met (ADB, 1995). Predictability is the consistency and reliability of institutions, their staffs, and their actions based on the institutions' stated objectives, policies, rules, and regulations, or to be able to foretell based on observation, experience, scientific reason, or stated processes (CARE Nepal, 2002; Maharjan et al., 2004). Predictability refers to the existence, equitable, and steady implementation of rules and policies to regulate the society (ADB, 1995).

Economic assets and organizational structures are crucial in assuring good governance practices (Roy and Tisdell, 1998). Despite the eminent importance of good governance in achieving 
sustainable development, there are only a few examples of countries and communities that have come somewhat close to achieving good governance in its totality (UNESCAP, 2009). Community forestry practices proved to be successful in forest resources conservation and utilization in Nepal. Hence, the handing over process was speeded up, which compromised various social and technical processes that are deemed necessary for the promotion of good governance practices. In addition, the post-handover support from the government and numerous service providers proved insufficient to compensate for the increasing demand of the increasing number of CFUGs. Because of this, the majority of the second-generation issues concerned with governance, equity, livelihood, and sustainable management of forests have emerged throughout the country (Kanel, 2004). In Nepal, there are only a few CFUGs that practice transparent and inclusive decision-making processes, proving that the contribution of community forests in supporting the poor, vulnerable, and marginalized members of the society has been very limited within CFUGs (Kanel and Subedi, 2004; Tiwari, 2002). The prevalence of the hierarchy system in the Nepalese society among the lower and higher castes, the rich and poor, and even gender discrimination poses a tremendous obstacle for the effective functioning of any development activities (Koirala et al., 2008). The poor and marginalized are somewhat discriminated in almost every aspect of management, and their opinions are given less preferences. The distribution of forest products is inequitable, and the interests of poor and disadvantaged group members are not properly incorporated where poor community forestry governance is practiced (Kanel and Niraula, 2004).

Poor people in rural areas rely on forest resources for their livelihood. However, a majority of the users do not even participate in the CFUG activities such as general assemblies (GAs), public hearings, training/workshops, and forest management activities. They lack access to information on policies, rules/regulations, and rights/responsibilities associated with decisions regarding allocation, access, distribution, and sharing of resources (Lamichhane and Parajuli, 2014). Elite people dominate in the decision-making processes regarding product distribution and fund mobilization by ignoring marginalized groups and families, which leads to very little involvement in decision-making processes and implementation of community activities. Representation of women, ethnic minorities, and Dalits in leadership positions at political, bureaucratic levels, and front lines is less than 3\% (Pokharel and Nurse, 2004). Recent studies have shown improvement in the representation of disadvantaged groups in leadership positions within CFUGs (Pokharel et al., 2011; Pokharel and Tiwari, 2013). Despite this improvement in representation, the status of 
governance in the CFUGs of Nepal is still not satisfactory. Community forestry in Nepal is based on the realm of decentralized participatory forest management approaches. Despite its well-documented history in addressing multi-faceted socio-economic and ecological issues, a range of challenges persists in governance aspects (Khatri et al., 2017; Lacuna-Richman et al., 2016). Ojha et al. (2020) pointed out that the governance in Nepal's forestry sector experiences a significant research policy gap. Understanding the status of governance of the community forestry that the participation of women, marginalized, and disadvantaged groups is nominal in decision-making processes in the community forestry practices of Nepal.

\section{Methods}

\section{Study Area}

Two CFUGs, Bosan and Hattiban Mahila, of Kathmandu district in Nepal, were selected as study sites. Both CFUGs are situated in the same geographical region and have completed at least one full period of operational plan, i.e., five years. The government has recognized

Table 1 : General characteristics of the selected CFUGs

\begin{tabular}{|l|l|l|}
\hline \multirow{2}{*}{ Date of Handover } & \multicolumn{1}{|c|}{ Bosan CFUG } & \multicolumn{1}{c|}{ Hattiban Mahila CFUG } \\
\cline { 2 - 3 } $\begin{array}{l}\text { Committee } \\
\text { Structure }\end{array}$ & $\begin{array}{l}\text { To51/03/20 } \\
\text { Males:5, Females: 6 }\end{array}$ & \multicolumn{1}{c|}{ 2059/03/26 } \\
\hline Area & 137.8 Hectares & Males: 1, Females:8 \\
\hline Types of Forest & Mix natural and plantation & Mix natural and plantation \\
\hline $\begin{array}{l}\text { Dominant } \\
\text { Tree } \\
\text { Species }\end{array}$ & $\begin{array}{l}\text { Uttis (Alnus nepalensis), } \\
\text { Khotesalla (Pinus roxburghii), } \\
\text { Chilaune (Schima wallichi), } \\
\text { Katus (Castanopsis indica) }\end{array}$ & $\begin{array}{l}\text { Uttis (Alnus nepalensis), } \\
\text { Khotesalla (Pinus roxburghii), } \\
\text { Chilaune (Schima wallichi), } \\
\text { Katus (Castanopsis indica) }\end{array}$ \\
\hline Forest Protection & $\begin{array}{l}\text { Hired forest watcher and } \\
\text { household otation }\end{array}$ & Household rotation \\
\hline $\begin{array}{l}\text { Number of } \\
\text { Households }\end{array}$ & $\begin{array}{l}\text { 261 households } \\
\text { Janajati: 229, Dalit: 4, }\end{array}$ & $\begin{array}{l}\text { 194 households } \\
\text { Janajati: 90, Dalit:14 } \\
\text { Others: 90 }\end{array}$ \\
\hline $\begin{array}{l}\text { Annual Allowable } \\
\text { Harvest (cubic feet) }\end{array}$ & 400 & 382.39 \\
\hline
\end{tabular}

sector in Nepal is that all-important first step for achieving sustainable forest management. Considering this, we assessed and compared the degree of the governance system in two CFUGs of Kathmandu, Nepal. Our study assumes both CFUGs for their performance in managing their forest land. Hattiban Mahila CFUG (hereafter referred to as Hattiban) was led by women, whereas Bosan CFUG (hereafter referred to as Bosan) had about equal 
representation of males and females in their executive committee (EC). A total of 261 households were present in Bosan, and 194 households were present in Hattiban. These households in Bosan and Hattiban managed and utilized forest areas of 137.8 hectares and 64.75 hectares, respectively (Table 1). Forest areas are mixed natural and plantation types, mostly dominated by Uttis (Alnus nepalensis), Khotesalla (Pinus roxburghii), Chilaune (Schima wallichi), and Katus (Castanopsis indica). The prescribed annual allowable timber harvest in their forest operational plan was 400 cubic feet for Bosan and 382 cubic feet for Hattiban (Table 1). The EC of Bosan consisted of 11 members, while Hattiban consisted of nine members (Table 1). conducted to verify the well-being ranking.

\section{Data Collection}

Taking the four key criteria of good governance (Participation, Transparency, Accountability, and Predictability) from the ADB (1995) into account, this study adopted four local indicators for each criterion (see RIMS Nepal, 2003) and assessed the status of governance in two CFUGs in Kathmandu, Nepal. Primary and secondary data were collected using participatory approaches. Stratified random sampling was used to identify the sample size for questionnaire surveys. We sampled 95 out of 455 total households representing all three wellbeing categories, out of which $79 \%$

Table 2 : Number of total and sampled households based on well-being ranking of the CFUG members as per the CFUG constitutions

\begin{tabular}{|l|l|l|l|}
\hline \multirow{2}{*}{ CFUG } & Well-off Households & Medium Households & Poor Households \\
\cline { 2 - 4 } & \multicolumn{1}{|c|}{ Sampled/Total } & \multicolumn{1}{c|}{ Sampled/Total } & Sampled/Total \\
\hline Bosan & $3 / 3$ & $44 / 228$ & $8 / 30$ \\
\hline Hattiban Mahila & $2 / 2$ & $31 / 167$ & $7 / 25$ \\
\hline Total & $5 / 5$ & $75 / 395$ & $15 / 55$ \\
\hline
\end{tabular}

\section{Well-being Ranking of CFUGs}

The well-being ranking was used to determine the relative economic status within the CFUGs. The constitutions of both CFUGs had identified the wealth status of each household and classified them into three categories: well-off, medium, and poor, based on their landholdings and land quality, type of house, food sufficiency, sources of income, and educational status (Table $2)$. Key in formant surveys $(n=5)$ were were in the "medium" category (Table $2)$. The questionnaire used for this study consisted of two major parts. The first part of the survey solicited socioeconomic characteristics such as age, gender, occupation, and educationof the respondents. The second part of the survey was designed to gatherinformation related to the four key criteria of good governance (Participation, Transparency, Accountability, and Predictability). The questionnaires were pretested and 
revised whenever necessary. In addition to the questionnaire surveys, focus group discussions $(n=4)$ with executive members and professional interest groups were carried out to collect data needed to answer the research questions. Direct observations that helped to triangulate the information gathered during focus group discussions and questionnaire surveys were also done. Additionally, to better understand the study area and supplement information obtained from the questionnaire survey, secondary data were collected from forestry user groups' constitution, community forestry operation plans, GA minute registers of the CFUGs, and attendance registers from the committee meetings. District Forest Office (DFO), Kathmandu records were reviewed to get information about the history of CFUGs and their progress status, rules, regulations, and decision-making procedures.

\section{Data Analysis}

Data collected from the surveys were analysed using qualitative and quantitative methods. Descriptive statistics, mainly mean and percentages, were used to interpret the results. The results were presented in tabular and graphical forms and used for discussions. To calculate the degree of governance status, the Asian Development Bank's four elements of good governance were considered (ADB, 1995). We adopted governance assessment matrices developed by RIMS, Nepal (2003) and Bhatta and Gentle (2004), and used those local indicators for our study areas. The data collected for each element with its indicators were scored on a scale of 1 to 4: (1) Poor, (2) Medium, (3) Good, and (4) Excellent (Table 3). The scoring scheme was derived from RIMS Nepal (2003) where each of the four indicators of all the four criteria was evaluated. For example, for the first indicators of the criteria 'Participation' which is 'Key/decision making position', a CFUG would receive a score of 4 (Excellent) if women or Dalits were in key positions of the EC, a CFUG would receive a score of 3 (Good) if there were women and Dalit representatives in the EC but not in key positions. Similarly, if the women representation in the $\mathrm{EC}$ was more than $33 \%$ of the total number of EC members, but there were no Dalit representatives, a CFUG would receive a score of 2 (Medium), and finally, a CFUG would receive a score of 1 (Poor) if the women representation in the EC was less than $33 \%$ of the total number of EC members with no Dalit representation in the EC. The maximum attainable score for each criterion was 16, and the lowest possible attainable score was 4 as each criterion has four indicators. The same information for each criterion was used to create a spider-web diagram as done by Bhatta and Gentle (2004) to visualize the status of governance in each CFUG. For the holistic governance status, as the four key criteria had four indicators, the total attainable score for each CFUG ranged from 16 to 64 (Table 3). Each element was then quantitatively and logically evaluated according to its score and ranked using the ranking table. 
Table 3 : Score and rank using the ranking table

\begin{tabular}{|l|c|c|c|c|}
\hline & Poor & Medium & Good & Excellent \\
\hline Indicator score & 1 & 2 & 3 & 4 \\
\hline Total score of each element & $1-4$ & $5-8$ & $9-12$ & $13-16$ \\
\hline Total score of 4 elements & 16 & $17-32$ & $33-48$ & $49-64$ \\
\hline
\end{tabular}

\section{Results}

\section{Socio-demographic Characteristics of the CFUGs}

The two CFUGs studied in this research had some similarities and differences in their socio-demographic characteristics. Among the four categories of age groups, $58 \%$ of the respondents were from the age group 31-45 years in Bosan, and $40 \%$ were between 15-30 years in Hattiban. This means that the majority of the respondents in this study were young members of the CFUGs. The males $(51 \%)$ and females $(49 \%)$ had almost equal representation in the study from Bosan, whereas most of the respondents $(67 \%)$ from Hattiban were females. In Bosan, most of the respondents $(87 \%)$ were from Janajati ethnic group, whereas Janajati $(46 \%)$ and others (46\%-Brahmin/Chhetri/ others) contributed equally to the survey response in Hattiban. More than onehalf of respondents for both CFUGs had a lower level of education (under SLC). In addition, agriculture was the main occupation of users from both CFUGs.

\section{Participation}

Active participation is one of the four pillars of good governance. Table 4 shows details of users' participation in the committee and activities carried out by the CFUGs. This study showed that both CFUGs had a good representation of women, poor, and Dalits in their executive committees. Women represented $55 \%$ of the total number of members in the EC of Bosan and $89 \%$ in that of Hattiban. However, the representation from Dalits in EC of both the CFUGs was relatively low (9\% in Bosan and $11 \%$ in Hattiban).

Respondents were asked about their actual participation in the decisionmaking processes of their CFUGs. The majority of respondents (63\% - Bosan and $70 \%$-Hattiban) revealed that they had never participated in the decision -making processes of their CFUGs. More than half $(62 \%)$ of the respondents from Bosan revealed that they were always informed prior to carrying out CFUG activities, in contrast to only $30 \%$ in Hattiban. Most of the respondents (approx. 70\%) from both the CFUGs participated in the forest management activities occasionally. Hence, the majority of them were satisfied with their participation in the user group decision-making processes, activities implementation, and benefit-sharing mechanisms.

\section{Transparency}

In Bosan, discussions with the members of EC revealed that the major income sources were the sale of forest products to the users, membership fees, subsidies 
Table 4 : User representation and attitude towards community forestry in both CFUGs

\begin{tabular}{|l|c|c|}
\hline \multicolumn{1}{|c|}{ Indicators of Participation } & Bosan CFUG (\%) & $\begin{array}{c}\text { HattibanMahila } \\
\text { CFUG (\%) }\end{array}$ \\
\hline Representation in the executive committee & & 11 \\
\hline Male & 45 & 89 \\
\hline Female & 55 & 45 \\
\hline Poor & 36 & 33 \\
\hline Janajati & 91 & 11 \\
\hline Dalits & 9 & 20 \\
\hline Participation in the decision-making process & & 10 \\
\hline Regularly & 13 & 70 \\
\hline Occasionally & 24 & 30 \\
\hline Never & 63 & 45 \\
\hline Prior information about community activities & & 25 \\
\hline Always informed & 62 & \\
\hline Often & 7 & 25 \\
\hline Never & 31 & 32 \\
\hline Participation in forest management activities & & 20 \\
\hline Regularly & 9 & 55 \\
\hline Occasionally & 69 & \\
\hline Never & 22 & \\
\hline Attitude towards participation & & 25 \\
\hline Fully satisfied & 40 & \\
\hline Somewhat satisfied & 22 & \\
\hline Not satisfied & & \\
\hline & & \\
\hline
\end{tabular}

from the District Forest Office, and donations from I/NGOs for carrying out forestry-related community activities as specified by them. The treasurer had successfully maintained clear records of all the financial transactions in a very systematic way. The financial status was usually made known to the users by public auditing during GAs. They had an account in Nepal Bank Limited with a net balance of Nepalese Rupees (NRs) 12,000 (equivalent to the US \$113). A similar type of discussion was also conducted in Hattiban, which revealed that the major sources of income in this CFUG were the sale of forest products to the local users and membership fees only. They had not received any subsidies and donations from anywhere. The treasurer had records of transactions but not in a very systematic manner. Financial status was generally not transparent to the public, and there had not been any public auditing done for the last ten years and more. They had a net balance of NRs 180,000 (equivalent to the US \$1,698) in the Namuna saving and credit co-operative, Dakshinkali-2, 
Kathmandu.

Table 5 shows summary of the users' responses on financial information for CFUGs. In both CFUGs, more than 90\% of the respondents were unaware of the where abouts of their group funds (Table 5). However, more than half of the respondents in Bosan (60\%) had knowledge about public auditing practices, whereas the majority of the respondents from Hattiban (83\%) did not. Most of the respondents (87\%) from Bosan, and surprisingly, all of the respondents $(100 \%)$ from Hattiban did not know about fund mobilization in their respective groups. More than half of the respondents in Bosan (60\%) said they had access to the financial records of their group in contrast to only $25 \%$ in Hattiban. Most of the respondents

Table 5 : User awareness, perception, and accessibility of financial information in CFUGs

\begin{tabular}{|c|c|c|}
\hline Indicators of Transparency & $\begin{array}{c}\text { Bosan } \\
\text { CFUG (\%) }\end{array}$ & $\begin{array}{c}\text { Hattiban Mahila } \\
\text { CFUG (\%) }\end{array}$ \\
\hline \multicolumn{3}{|l|}{ Awareness about group funds } \\
\hline Yes & 9 & 7 \\
\hline No & 91 & 93 \\
\hline \multicolumn{3}{|l|}{ Knowledge about CFUG public audits } \\
\hline Yes & 60 & 12 \\
\hline No & 23 & 55 \\
\hline Don't know & 17 & 33 \\
\hline \multicolumn{3}{|l|}{ Awareness of fund mobilization } \\
\hline Yes & 13 & 0 \\
\hline No & 87 & 100 \\
\hline \multicolumn{3}{|l|}{ Accessibility of financial records } \\
\hline Yes & 60 & 25 \\
\hline No & 40 & 75 \\
\hline \multicolumn{3}{|c|}{ Information about the decision of the executive committee } \\
\hline Yes & 28 & 12 \\
\hline No & 72 & 88 \\
\hline \multicolumn{3}{|l|}{ Pricing for forest products } \\
\hline Price determined by the executive committee & 80 & 93 \\
\hline Price based on the constitution & 6 & 0 \\
\hline Users group & 0 & 0 \\
\hline Don't know & 14 & 7 \\
\hline \multicolumn{3}{|c|}{ Respondents' perception of the distribution of forest products } \\
\hline Equal basis & 71 & 75 \\
\hline Equity basis & 4 & 0 \\
\hline Biased & 20 & 17 \\
\hline Don't know & 5 & 8 \\
\hline
\end{tabular}


from both CFUGS (72\% - Bosan, 88\% - Hattiban) were not informed about the decisions of the EC. Similarly, in both CFUGs, most of the respondents (80\% - Bosan, 93\% - Hattiban) said that the price of the forest products was determined by the EC. Moreover, the majority of the respondents from both CFUGs (71\% - Bosan, 75\% -Hattiban) perceived that forest products were equally distributed among all the users.

\section{Accountability}

The summary of the respondents' opinions on the roles and responsibilities of the EC is shown in Table 6. In
As for Hattiban, the percentages of total respondents who reported that the EC was fully, partially, and not at all responsible to the users were 30 , 50 , and 20 , respectively. The majority of the respondents $(71 \%)$ in Bosan were satisfied with their EC but not in Hattiban (35\%). In Bosan, $62 \%$ of the respondents reported that they were informed prior to carrying out every activity of the user group, whereas only $30 \%$ in Hattiban reported they were always informed. More than half of the respondents $(54 \%)$ in Bosan perceived that they were never discriminated

Table 6: Users' perception and attitude towards the roles and responsibilities of EC

\begin{tabular}{|l|c|c|}
\hline \multicolumn{1}{|c|}{ Indicators of Accountability } & BosanCFUG (\%) & Hattiban Mahila CFUG (\%) \\
\hline Perception of accountability of executive members \\
\hline Fully accountable & 66 & 30 \\
\hline Partially accountable & 14 & 50 \\
\hline Not accountable & 11 & 20 \\
\hline Do not know & 9 & 0 \\
\hline Attitude towards roles and responsibilities of executive members \\
\hline Satisfied & 71 & 35 \\
\hline Not satisfied & 4 & 38 \\
\hline Do not know & 25 & 27 \\
\hline Prior information about group activities \\
\hline Yes & 62 & 30 \\
\hline No & 31 & 70 \\
\hline Perception of committee's behavior towards disadvantaged groups \\
\hline No discrimination & 54 & 28 \\
\hline Partial discrimination & 20 & 42 \\
\hline Discrimination & 26 & 30 \\
\hline
\end{tabular}

Bosan, $66 \%, 14 \%$, and $11 \%$ of the total respondents reported that the EC was fully, partially, and not at all accountable to the users, respectively. by their EC, but the majority of the respondents $(72 \%)$ in Hattiban reported that they felt there was some sort of discrimination. 


\section{Predictability}

In Bosan, annual plans were made during the annual meetings/GAs, and the decisions were carefully noted in minute books. Regular monthly meetings ensured that proper measures were taken to carry out those plans effectively. Directives/ guidelines for making bio-briquettes had been prepared. The constitution had been revised for the third time in the year 2069 B.S., and the OP had been revised every five years. As for Hattiban, it had been more than ten years since the last annual meeting/GA took place. They had not made any annual plans/guidelines or directives for any purpose. Their constitution and OP had been last revised in the year 2070 B.S., which were then valid up to the year 2075 B.S. Bosan had good linkages with the District Forest Office (DFO), Department of Livestock Services (DLS), Federation of Community Forestry Users Nepal (FECOFUN), and District Forest Coordination Committee (DFCC). It also had good networking with Non-Governmental Organizations (NGOs) such as Oxfam, Asia Pacific Forest Network (APFNet), Share and Care Medico Nepal, and few local cooperatives. Hattiban, on the other hand, had a good link with DFO but poor links with DLS and FECOFUN. It did not have any linkages with NGOs.

Bosan had good linkages with both governmental and non-governmental organizations and conducted many collaborative programs with help from these organizations in the past. DFO had provided subsidies and training related to forest management activities in the past as well for the grafting of Lapsi (Choerospondias axillaris). DLS, as well as a local co-operative (Namuna Co-operative), had aided inthe plantation of high yielding grass species. APF Net had helped them by providing forest management training, the rebuilding of infrastructures, and awareness regarding women empowerment. Oxfam did various forest management activities such as cleaning and construction of fire lines by providing incentives and subsidies. Lack of proper coordination with various agencies resulted in poor exposure of Hattiban, which in turn made it very difficult for them to bring in projects or aids from governmental and non-governmental organizations. Users were not aware of such programs, and the EC was neither responsive nor interested in bringing such assistance to their CFUG.

Bosan had set some goals and visions for forest development, community development, and utilization of their forest resources in an eco-friendly way. Bosan had a hiking trail leading to Champadevi hill, which is a popular destination among domestic and international tourists. The user group had plans for establishing a small zoo and several animal enclosures along the trail for the visitors. Various plans for ecotourism activities had been made. In addition, better provisions of drinking water and electricity for the local inhabitants were major focus points of Bosan. They had planned 
to initiate some Income Generating Activities (IGAs) too for the betterment of poor and marginalized people. On the contrary, Hattiban did not have any sort of goals and visions for the future. The EC was struggling to stay on good terms with the general users, and as almost all members in the EC were females, they reported that they were dominated and hindered by males whenever they tried to do some activities instead of receiving support. Hence, this CFUG lacked a clear vision, goals, and objectives.

\section{Level of Good Governance in the CFUGs}

The total score of each criterion/element of good governance from both the CFUGs was transformed into a spider web diagram to get a graphical representation of the degree/status of good governance (Figure 1). The diagram (Figure 1) shows the ideal status (a perfect score of 16 for each of the four criteria/elements: Participation, Transparency, Accountability, and Predictability) and the scores of all four criteria/elements for Bosan and Hattiban. Hattiban was weak in Transparency, Accountability, and Predictability criteria of good governance compared with Bosan of the same locality/geographic region. The main reason was a lack of support from supporting line agencies, which made the users capable of good governance practices.

\section{Discussion}

The study examined the governance status of two community-managed forests. Except for Participation, three other criteria: Transparency, Accountability, and Predictability, were considered better in Bosan than in Hattiban. The ECs of both the CFUGs were satisfactorily structured with proper representation of females, Dalits, and Janjatis in key positions. However, there wasa lack of females willing to serve in volunteer positions because of gender discrimination (Pokharel and Tiwari, 2013). Bhandari et al. (2018) showed that gender and EC (user group

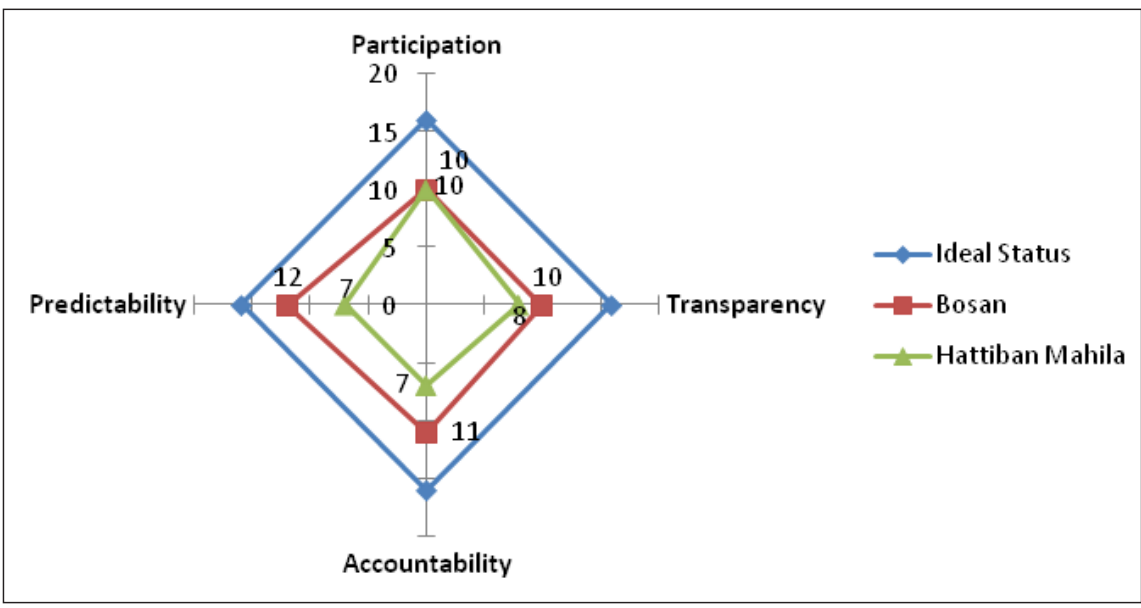

Figure 1 : Status of good governance practices in both CFUGs in a spider web diagram 
committee members) had a significant effect on the degree of participation. In this study, only the ECs took most of the decisions regarding forest management activities, pricing of the forest products, and sharing of benefits in both CFUGs. Forest products in both the CFUGs were distributed on an equal basis rather than on an equity basis. People's participation in group meetings and decision-making processes in both the CFUGs was found low because of a lack of prior information, a busy schedule, and hesitation among the users. A similar study carried out by Lamichhane and Parajuli (2014) found that poor users were unable to participate and carry out leadership roles because they were not compensated for their time and efforts. Nonetheless, those who participated, women, poor, and Dalits, raised their voices in group meetings, and many had reported they were heard most of the time. This finding contradicts the studies carried out by Rasaily (1996) and Thapa et al. (1998), where they had found that the opinions from the females and disadvantaged groups were not considered while making decisions. These findings between our study and the previous studies, Rasaily (1996) and Thapa et al. (1998) suggest that the level of awareness among the members of CFUGs is increasing in due time to some extent. Despite this, regular participation of the users in group meetings of both the CFUGs was found poor because of improvement in living standards and less feeling of ownership in the users. It was found that most of them did not need the resources from their community-managed forest. Therefore, they were not willing to give time or to get involved in communitybased activities.

Another element of governance, Transparency, was better in Bosan than in Hattiban. Bosan had regular monthly meetings, public audits, and GAs. However, only a few users knew about their revolving funds. The major issues of Hattiban were irregular GAs, the absence of public audits, and irregular committee meetings. Similar findings were reported by Kanel (2004), where they identified a lack of proper communication regarding fund mobilization and transparency in financial transactions to be the key challenges of community forestry in Nepal. Of many reasons, lack of interest and support from users as well as the weak influence of CFUG executive committee members resulted in more debates and trust issues inside the user groups. It is mandatory to use a certain amount $(30 \%-50 \%)$ of the group funds in community development and forest protection activities. Despite the fact that economic motivation is one of the major factors of people's participation in various community activities (Kimengsi et al. 2019), no funds had been utilized for forest protection, development, poverty alleviation, or in the form of institutional development in any of the two CFUGs. The majority of the users from both CFUGs did not know about their own constitution and $\mathrm{OP}$, and also did not know about the 
decisions made by their EC in the last meeting. Similar findings were reported in the study by Lamichhane and Parajuli (2014); many users, along with the EC, were not clearly aware ofthe provisions mentioned in their constitution and OP.All the decisions regarding pricing and distribution of forest products were made only by the EC, and the general members did not have any say in this matter whatsoever.

Every EC must be accountable to theusers (Kanel and Kandel, 2004). However, making CFUG accountable and responsive is one of the major challenges in CF (Kanel, 2004). This study found that the EC of Bosan was relatively more accountable than Hattiban to its users. However, no specific program for poor and marginalized had been conducted. In terms of benefit sharing, forest products were distributed in a balanced way. Such types of practices where everyone is given an equal share have been shown to create dissatisfaction among many poor users as they believe benefits must be shared on an equity basis (Lamichhane and Parajuli, 2014).

In terms of Predictability, Bosan had a clear vision for community development, ecotourism promotion, and income - generating activities. The group had already developed a guideline for establishing microenterprises such as a bio-briquette company. This would help create local job opportunities to increase the income of the users, which in turn would support the group funds. To run any enterprise successfully, outsourcing of raw materials, marketing, and networking are very important. Bosan already had better networking with various governmental and nongovernmental organizations, which had been supporting them to carry out many CFUG related activities such as plantations, cleanings, and training related to forest management. A previous study by Stapp et al. (2015) also showed the positive impact of various governmental and non-governmental organizations on forest management activities. In contrast, Hattiban did not have any plan for community development activities and lacked a clear goal and vision. Also, it had a poor network with service providing agencies that prevented them from carrying out community development and forest management activities.

Community forestry in Nepal has played a vital role in poverty alleviation since its inception. This role of community forestry is going to be even more crucial in the context of the new federal system of Nepal, where local governments are given more authority for natural resources management. However, making CFUG representatives accountable to the users, proper implementation of the operational plan and constitution, transparent accounting and efficient mobilization of public resources, in corporating opinions of the poor users in decision making, and implementation of equitable benefitsharing mechanisms were some of the key issues of good governance of $\mathrm{CF}$ in Nepal. Thus, to address these issues, 
it is necessary to comprehend the situation of community forestry by the government and concerned stakeholders to meet the intent of community forestry programs in the context of the new federal system. Doing this will create a win-win situation where both the local economy and ecology will be improved.

\section{Conclusion}

This study showed that the overall status of governance in Bosan was 'Good' whereas that in Hattiban was 'Medium.' Levels of Transparency, Accountability, and Predictability were higher in Bosan, with all of them falling in the 'Good' category while the degree of the same elements in Hattiban was only 'Medium.' Degree of Participation, however, in both the CFUGs was 'Good.' It is because both CFUGs had better participation in the implementation of group activities. A more significant number of users in Bosan were more aware of the financial activities, provisions mentioned in their OP and constitution, benefit-sharing, and roles and responsibilities towards mutual interest of the group. In addition, the $\mathrm{EC}$ of Bosan was comparatively more active in coordination, networking, and linkage with backstopping agencies such as DFO, I/NGOs, and other stakeholders. This was probably due to higher self-motivation and level of awareness regarding the proper utilization of the community forest for the benefit of the commons.

This study also identified several challenges faced by CFUGs while managing forestlands and carrying out community activities. Lack of interest, coordination, and information dissemination among users, the hegemony of elite groups, and lack of awareness about potential benefits from well-managed forestlands were a few of the issues and challenges of CFUGs. In Nepal, the literacy rate of women is lower than that of men because of which they show lower confidence in decision making and its implementation. In addition, women have more workload in their homes, which they must prioritize over community activities.

To practice good governance in community forestry, the level of awareness among the users must be improved through hands-on learning experiences and extension programs. Women and marginalized groups must be empowered and encouraged to conduct activities for their own benefits, as well as the development of their community. Income-generating activities must be endorsed to encourage active participation. Regular monitoring and evaluation should be implemented effectively and efficiently. Provision of timely public audits, general assemblies, and monthly meetings must be ensured. The policymakers and governmental agencies must strengthen their network with the CFUGs for better financial and technical assistance so that they can conduct various activities in the group for ensuring good governance while considering forest management and biodiversity conservation. 
Acknowledgments

The authors would like to express sincere thanks to the independent reviewers for providing useful comments and suggestions to improve the quality of the manuscript. The authors are grateful to all users of Bosan and Hattiban Mahila CFUGs who provided their valuable time to respond to the survey and Mr. Milan Panthi for his unwavering assistance with the field study.

\section{Conflicts of Interest}

The authors declare no conflict of interest.

\section{References}

Asian Development Bank. 1995. Governance: Sound Development Management, viewed on 4 June 2020, http://www. adb.org/sites/default/files/institutionaldocument/32027/govpolicy.pdf

Bhandari, P.K.C., Bhusal, P., Khanal Chhetri, B.B. and Upadhyaya, C.P. 2018. LookingWomen Seriously: What Makes Differences for Women Participation in Community Forestry. Banko Janakari, 28(2): 13-22.

Bhatta, B. and Gentle, P. 2004. Strengthening the Internal Governance of the CFUGs: Experience of SAMARPAN Project. In K. R. Kanel, P. Mathema, B. R. Kandel, D. R. Niraula, A. R. Sharma, and M. Gautam (Eds.), Proceedings of the 4th National Workshop on Community Forestry, Twenty-Five Years of Community Forestry (p. 587). Kathmandu: Department of Forests.

CARE Nepal. 2002. SAGUN Technical Proposal. Care Nepal, Lalitpur, Nepal.

FAO. 2020. Natural Forest Management, viewed on 4 June 2020, http://www.fao. org/forestry/sfm/en/

Hyden, G. and Court, J. 2002. Governance and Development - World Governance
Survey Discussion Paper 1 (pp. 1-34), viewed on 4 June 2020, http://www.odi.org/sites/odi.org. uk/files/odi-assets/publications-opinionfiles/4094.pdf

ICIMOD. 2004. Introduction to Good Silviculture Practices in Community Forests: Experience of Community Forest Management Demonstration Programme. In K. R. Kanel, P. Mathema, B. R. Kandel, D. R. Niraula, A. R. Sharma, and M. Gautam (Eds.), Proceedings of the 4th National Workshop on Community Forestry, Twenty-Five Years of Community Forestry (p. 587). Kathmandu: Department of Forests.

Kanel, B. R. and Subedi, R. 2004. Pro-Poor Community Forestry: Some Initiatives From the Field. In K. R. Kanel, P. Mathema, B. R. Kandel, D. R. Niraula, A. R. Sharma, and M. Gautam (Eds.), Proceedings of the 4th National Workshop on Community Forestry, Twenty-Five Years of Community Forestry (pp. 229-237). Kathmandu: Department of Forests.

Kanel, K. R. 2004. Twenty-Five Years of Community Forestry: Contribution to Millenium Development Goals. In K. R. Kanel, P. Mathema, B. R. Kandel, D. R. Niraula, A. R. Sharma, and M. Gautam (Eds.), Proceedings of the 4th National Workshop on Community Forestry, Twenty-Five Years of Community Forestry (pp. 4-30). Kathmandu: Department of Forests.

Kanel, K. R. and Kandel, B. R. 2004. Community Forestry in Nepal: Achievements and Challenges. Journal of Forest and Livelihood, 4(1): 55-63.

Kanel, K. R. and Niraula, D. R. 2004. Can Rural Livelihood be Improved in Nepal through CF? Banko Janakari, 14(1): 19-26.

Khatri, D., Shrestha, K., Ojha, H., Paudel, G., Paudel, N. and Pain, A. 2017. Reframing Community Forest Governance for Food Security in Nepal. Environmental Conservation, 44(2), 174-182. https://doi. org/10.1017/S0376892916000369 
Kimengsi, J.N., Bhusal, P., Aryal, A., Fernandez, M.V.B.C., Owusu, R., Chaudhary, A. and Nielsen, W. 2019. What (De) Motivates Forest Users' Participation in Co-Management? Evidence from Nepal. Forests, 10(6): 1-15. https://doi. org/10.3390/f10060512

Koirala, R., Giri, K. and Pokharel, B. K. 2008. Development and Status of Community Forestry Governance in Nepal. In M. S. Ashton, T. G. Gregoire, C. D. Oliver, and J. G. Speth (Eds.), 2008 Society of American Foresters National Convention. "Forestry in a Climate of Change". Reno-Tahoe, Nevada, USA: Society of American Foresters.

Lacuna-Richman, C., Devkota, B. P. and Richman, M. A. 2016. Users' Priorities for Good Governance in Community Forestry: Two Cases from Nepal's Terai Region. Forest Policy and Economics, 65: 69-78. $\quad$ https://doi.org/10.1016/j. forpol.2015.11.005

Lamichhane, D. and Parajuli, R. 2014. How Good is the Governance Status in Community Forestry? A Case Study from Midhills in Nepal. Journal of Ecosystems, 2014, 1-7. https://doi.org/10.1155/2014/541374

Maharjan, M. R., Acharya, B., Lamichhane, R. P., Sharma, N. N., Pradhan, B. R. and Paudel, T. P. 2004. Operationalization of Good Governance in Community Forestry: An Experience from SAGUN Program. In K. R. Kanel, P. Mathema, B. R. Kandel, D. R. Niraula, A. R. Sharma, and M. Gautam (Eds.), Proceedings of the 4th National Workshop on Community Forestry, Twenty-Five Years of Community Forestry (p. 587). Kathmandu: Department of Forests.

Ojha, H., Regmi, U., Shrestha, K. K., Paudel, N. S., Amatya, S. M., Zwi, A. B., Nuberg, I., Cedamon, E. and Banjade, M. $R$. 2020. Improving Science-Policy Interface: Lessons from the Policy Lab Methodology in Nepal's Community Forest Governance. Forest Policy and Economics, 114. https://doi. org/10.1016/j.forpol.2019.101997

Pokharel, B. K. and Nurse, M. 2004. Forests and People's Livelihood: Benefiting the Poor from Community Forestry. Journal of Forest and Livelihood, 4(1): 19-29.

Pokharel, R. K., Gyawali, A. R., Yadav, R. L. and Tiwari, K. R. 2011. Increasing Women Access to Financial Resources Through Micro-Credit of Nepal's Community Forestry. International Journal of Social Forestry, 4(1): 1-16.

Pokharel, R. K. and Tiwari, K. R. 2013. Good Governance Assessment in Nepal's Community Forestry. Journal of Sustainable Forestry, 32(6): 549-564. https://doi.org/10.1080/10549811.2013 .779902

Rasaily, L. 1996. Benefit Sharing and Social and Institutional Decision Making Process with Selected Forest User Groups. Project report B/NUCKFP/33: NepalUK Community Forestry Project. Dhankuta, Nepal.

RIMS Nepal. 2003. Good Governance Practices in Community Forestry Management. A Case Study of Selected CFUGs in Gajuri, Dhading.

Roy, K. C. and Tisdell, C. A. 1998. Good Governance in Sustainable Development: The Impact of Institutions. International Journal of Social Economics, 25(6/7/8): 1310-1325. https://doi. org/10.1108/03068299810212775

Stapp, J.R., Lilieholm, R.J., Upadhaya, S. and Johnson, T. 2015. Evaluating the Impacts of Forest Management Policies and Community-Level Institutions in the Buffer Zone of Chitwan National Park, Nepal. Journal of Sustainable Forestry, 34(5):445-464. https://doi.org/10.1080/ 10549811.2015.1025080

Thapa, K. B. 2005. An Assessment of Governance Status of CFUGs in Banke District, Nepal. (Unpublished B.Sc. Thesis). Tribhuvan University, Kathmandu, Nepal.

Thapa, S., Shrestha, R. N. and Yadav, K. P. 1998. Socio-Economic Aspects of the Followup Forest Resource Assessment Study. Project Report B/ NUKCFP/55: NepalUK Community Forestry Project. Kathmandu, Nepal. 
Tiwari, S. 2002. Access, Exclusion \& Equity Issues in Community Management Forests: An Analysis of Status of CFs in MidHills of Nepal. Winrock International. Kathmandu, Nepal.

UNDP. 1997. Governance for Sustainable Human Development - Policy Document. United Nations Development Programme (UNDP). New York.

UNESCAP. 2007. Access to Basic Services for the Poor: the Importance of Good Governance. United Nations Economic and Social Commission for Asia and the Pacific (UNESCAP).

UNESCAP. 2009. United Nations Economic and Social Commission for Asia and the Pacific, viewed on 4 June 2020, https://www.unescap. org/resources/what-good-governance

Zoysa, M. D. and Inoue, M. 2008. Forest Governance and Community Based Forest Management in Sri Lanka: Past, Present and Future Perspectives. International Journal of Social Forestry, 1(1): 27-49. 